\title{
Influence of osmotic stress on the profile and gene expression of surface layer proteins in Lactobacillus acidophilus ATCC 4356
}

\author{
María Mercedes Palomino $^{1}$ • Pablo M. Waehner ${ }^{1}$. Joaquina Fina Martin ${ }^{1}$. \\ Paula Ojeda $^{1}$ • Lucía Malone ${ }^{1}$ - Carmen Sánchez Rivas ${ }^{1}$ - Mariano Prado Acosta ${ }^{1}$. \\ Mariana C. Allievi ${ }^{1} \cdot$ Sandra M. Ruzal ${ }^{1}$
}

Received: 23 March 2016 /Revised: 12 June 2016 / Accepted: 19 June 2016

(C) Springer-Verlag Berlin Heidelberg 2016

\begin{abstract}
In this work, we studied the role of surface layer (Slayer) proteins in the adaptation of Lactobacillus acidophilus ATCC 4356 to the osmotic stress generated by high salt. The amounts of the predominant and the auxiliary S-layer proteins SlpA and SlpX were strongly influenced by the growth phase and high-salt conditions $(0.6 \mathrm{M} \mathrm{NaCl})$. Changes in gene expression were also observed as the mRNAs of the $\operatorname{sip} A$ and $\operatorname{sip} X$ genes increased related to the growth phase and presence of high salt. A growth stage-dependent modification on the S-layer protein profile in response to $\mathrm{NaCl}$ was observed: while in control conditions, the auxiliary SlpX protein represented less than $10 \%$ of the total S-layer protein, in high-salt conditions, it increased to almost $40 \%$ in the stationary phase. The increase in S-layer protein synthesis in the stress condition could be a consequence of or a way to counteract the fragility of the cell wall, since a decrease in the cell wall thickness and envelope components (peptidoglycan layer and lipoteichoic acid content) was observed in $L$. acidophilus when compared to a non-S-layer-producing species such as Lactobacillus casei. Also, the stationary phase and growth in high-salt medium resulted in increased release of S-layer proteins to the supernatant medium. Overall, these
\end{abstract}

María Mercedes Palomino and Pablo M. Waehner contributed equally to this work.

Electronic supplementary material The online version of this article (doi:10.1007/s00253-016-7698-y) contains supplementary material, which is available to authorized users.

Sandra M. Ruzal

sandra@qb.fcen.uba.ar

1 Laboratorio Bacterias Gram Positivas, sus Fagos y Estrés, Departamento de Química Biológica, Facultad de Ciencias Exactas y Naturales-UBA, IQUIBICEN-CONICET, Ciudad Universitaria, Pabellon II, piso 4, Buenos Aires 1428, Ciudad de Buenos Aires, Argentina findings suggest that pre-growth in high-salt conditions would result in an advantage for the probiotic nature of $L$. acidophilus ATCC 4356 as the increased amount and release of the S-layer might be appropriate for its antimicrobial capacity.

Keywords S-layer proteins $\cdot$ Lactobacillus $\cdot$ Osmotic stress

\section{Introduction}

Surface-layer (S-layer) proteins are ubiquitous in both Eubacteria and Archaea. S-layers are arrays of a single protein that constitutes the outermost cell envelope and have been considered to function as protective coats, maintenance of cell shape, and adhesion to specific hosts (Avall-Jääskeläinen and Palva 2005; Hynönen and Palva 2013; Gerbino et al. 2015). In addition, we have recently shown that the S-layer of Lactobacillus acidophilus has antibacterial endopeptidase activity and antiviral functions (Prado-Acosta et al. 2008, 2010; Martínez et al. 2012). S-layer proteins are present in some Lactobacillus species that are normal inhabitants of the oral and genital cavities and the gastrointestinal tract (GIT) of humans and animals and that are generally recognized as safe (GRAS). L. acidophilus is one of the species found in the human intestine, and some strains are used as probiotics (Resta-Lenert and Barrett 2003). Probiotics play an important role in the control of the host intestinal microbiota and in the modulation of the host immune response. It is generally assumed that a good adherence capacity is a desirable trait for probiotic lactobacilli, as it can promote the gut residence time, pathogen exclusion, and interaction with host cells for the protection and immunomodulation of the epithelium (Buck et al. 2005; Frece et al. 2005). By proteome analysis, in an adherence assay using Caco-2 cells, Ashida et al. (2011) identified S-layer proteins of L. acidophilus L-92, including SlpA. In other studies, Klaenhammer et al. (2005) reported an slpA mutant of 
L. acidophilus NCFM as being more resistant to bile and more sensitive to $\mathrm{NaCl}$ and ethanol. Furthermore, studies regarding the structure and gene expression of the S-layer proteins of L. acidophilus ATCC 4356 (Oling et al. 2001; Smit et al. 2002) and their biological functions have been conducted (Ramiah et al. 2009; Khaleghi et al. 2010; Khaleghi and Kermanshahi 2012), but the effect of salt stress on this strain has not been evaluated. In contrast, in L. acidophilus NCFM, the genes responding to salt stress (Weiss and Jespersen 2010) and the effect of GIT conditions on slp gene expression have been studied by several authors (O'Flaherty and Klaenhammer 2010; Capozzi et al. 2011).

In our laboratory, we have studied the response to osmotic stress of several gram-positive strains and species and observed several cell envelope modifications when Bacillus or Lactobacillus strains were exposed to high-salt conditions (Lopez et al. 2000; Piuri et al. 2003, 2005; Palomino et al. $2009,2010,2013)$. In particular, we have shown that growth in high-salt conditions of Lactobacillus casei BL23, a species that lacks S-layers, causes several pleiotropic effects, including differences in the susceptibility to enzymatic lysis, increased sensitivity to cationic antimicrobials such as nisin, and increased capacity to form biofilm on artificial surface and transformation ability. These modifications result both from the changes in the peptidoglycan structure and the different zwitterion character of the lipoteichoic acid (LTA) molecule in high-salt conditions (Piuri et al. 2005; Palomino et al. 2010, 2013).

Growth under high-salt conditions is of industrial importance, because $\mathrm{NaCl}$ concentration is $0.3 \mathrm{M}$ in the gut when lactobacilli are used as a probiotic and about $0.35 \mathrm{M}(2 \% \mathrm{w} / \mathrm{v})$ and up to $0.6 \mathrm{M}$ (about $3.5 \% \mathrm{w} / \mathrm{v}$ ) in cheeses (Crow et al. 1995; Fox et al. 1996). Pre-growth in high salt prior to lyophilization increases bacterial survival after the process, an important quality in the starter culture industry (Kets et al. 1996; Koch et al. 2007). Although $\mathrm{NaCl}$ concentration in food preservation is high, it is mild in the GIT. However, pre-growth of bacteria in hyperosmotic conditions to develop a probiotic formula might result in a better performance for probiotic applications. In fact, evaluation of the LTA content, as that described for L. casei (Palomino et al. 2013), is necessary to determine the characteristics of probiotics regarding inflammatory reactions as a consequence of their LTA content (Mohamadzadeh et al. 2011; Lebeer et al. 2012) or antiinflammatory effects (Kim et al. 2014; Kaji et al. 2010).

We have recently sequenced the genome of $L$. acidophilus ATCC 4356 (Palomino et al. 2015), a strain whose probiotic nature has been well documented (Resta-Lenert and Barrett 2003). Similarly to the NCFM strain (Goh et al. 2009), we found three S-layer-protein-coding genes: $\operatorname{slp} A, \operatorname{sip} B$, and slpX. Ramiah et al. (2009) have shown an increased expression of the $\operatorname{slp} A$ gene when grown in GIT conditions. However, their study was performed in actively growing cells, a condition that is not found in the GIT where cell division is expected to be low, resembling a stationary phase state. Therefore, when analyzing S-layer and envelope structure biosynthesis that occurs mainly during cell division, they should be evaluated both in the exponential and stationary phases to be able to mimic the GIT environment.

In this work, we studied the influence of the growth phase and osmotic stress on the profile and gene expression of Slayer proteins in the adaptation of L. acidophilus ATCC 4356 to high-salt medium.

\section{Materials and methods}

L. acidophilus ATCC 4356 and L. casei BL23 were grown at $37{ }^{\circ} \mathrm{C}$ in de Man, Rogosa and Sharpe (MRS) medium (low salt control conditions). MRS medium (Biokar, Beauvais, France) $\mathrm{pH}=6.5$ contains $10 \mathrm{~g}$ tryptone $\mathrm{l}^{-1}$, $4 \mathrm{~g}$ yeast extract $\mathrm{l}^{-1}, 8 \mathrm{~g}$ meat extract $\mathrm{l}^{-1}, 5 \mathrm{~g} \mathrm{Na}$ acetate $\mathrm{l}^{-1}, 0.2 \mathrm{~g} \mathrm{MgSO}_{4} \cdot 7 \mathrm{H}_{2} \mathrm{O} \mathrm{l}^{-1}, 0.05 \mathrm{~g} \mathrm{MnSO}_{4} \cdot 4 \mathrm{H}_{2} \mathrm{Ol}^{-1}$, and $1 \mathrm{ml}$ Tween $80 \mathrm{l}^{-1}$ and $20 \mathrm{~g}$ glucose $\mathrm{l}^{-1}$. The stress condition was obtained by adding $0.3,0.4,0.45,0.6$, or $0.8 \mathrm{M}$ $\mathrm{NaCl}$ (high-salt conditions).

Purified S-layer proteins from Lactobacillus cultures grown in MRS medium at $37{ }^{\circ} \mathrm{C}$ were extracted by using $5 \mathrm{M} \mathrm{LiCl}$, then extensively dialyzed against distilled water overnight at $4{ }^{\circ} \mathrm{C}$ and, after centrifugation $(10,000 \times g$, $20 \mathrm{~min}$ ), suspended in sterile phosphate-buffered saline (PBS) and stored at $-20^{\circ} \mathrm{C}$.

Cells from cultures grown in control or high-salt medium were peeled from their S-layer by treatment with $5 \mathrm{M} \mathrm{LiCl}$. After removal of $\mathrm{LiCl}$ by washing with physiological solution, cells were inoculated in MRS medium at $37^{\circ} \mathrm{C}$ with or without $\mathrm{NaCl}$ and their growth was monitored by optical density at $600 \mathrm{~nm}(\mathrm{OD} 600)$ and viable counts.

Whole cells $(20 \mu \mathrm{l}$ OD600 $=5$ overloaded for western blot or $10 \mu \mathrm{l}$ OD $600=1$ for Coomassie staining or S-layer preparations $(20 \mu \mathrm{g})$ were heated at $90{ }^{\circ} \mathrm{C}$ for $5 \mathrm{~min}$ in loading buffer (10\% glycerol, $4 \%$ sodium dodecyl sulfate (SDS), $4 \mathrm{M}$ urea, $2 \% \beta$-mercaptoethanol, and $0.05 \%$ bromophenol blue) and subjected to electrophoresis in $12.5 \%$ SDS-PAGE. Gels were stained with Coomassie Brilliant Blue (Sigma-Aldrich, St. Louis, MO, USA). Zymography was performed as described in Prado-Acosta et al. (2008). Polyacrylamide gels were cast with $0.01 \%$ SDS. After the run, hydrolase activity was detected by a clear zone.

For western blot analysis, gels were electrotransferred with a semi-dry blotter (Amersham Biosciences, Chicago, USA) to PVDF membranes (Macherey-Nagel, Düren, Germany) soaked with mouse polyclonal antibodies against the S-layer (diluted 1:5000) (Prado-Acosta et al. 2008) and visualized with biotin-conjugated anti-mouse antibody followed by streptavidin-HRP conjugate (Pierce Biotechnology, 
Rockford, IL, USA). Chemiluminescence was detected with luminol substrate ECL (Amersham, GE Healthcare, Chicago, USA). Images were obtained with a G:Box Chemi XT4 digitalizer (Syngene, Cambridge, UK).

Supernatants of exponential and stationary phase cultures were concentrated with Centrisart I SM132 49 devices with 20-kDa cutoff (Sartorius, Göttingen, Germany) by centrifugation at $2500 \times g$ to achieve a 20 -fold concentration. Equal volumes were loaded on SDS-PAGE $12.5 \%$, and western blot was performed of each condition.

qPCRs of $\operatorname{slp} A, \operatorname{sip} B$, and $\operatorname{slp} X$ gene transcription were verified in exponential and stationary phase conditions for control (MRS) and high salt $(0.45$ and $0.6 \mathrm{M} \mathrm{NaCl})$ from complementary DNA (cDNA) samples, using MyiQ realtime thermal cycler (Bio-Rad, Berkeley, CA, USA). cDNA was synthesized with 25 pmol reverse primers of each gene and $3 \mathrm{mg}$ of RNA. The mixtures were incubated at $95^{\circ} \mathrm{C}$ for $10 \mathrm{~min}$, kept for $2 \mathrm{~min}$ on ice, and incubated with $100 \mathrm{U}$ of MMLV reverse transcriptase (Promega, Fitchburg, WI, USA), according to the manufacturer's recommendations. For RNA extraction, the hot phenol method was used (Palomino et al. 2013), using the following gene-specific primers designed from unique nucleotide sequences not shared by the slp genes, as shown in Supplemental Fig. S1 and Table S1. Forward primers were as follows: 5'-GCGAAGGCGGCTGTCTGG3' for $16 \mathrm{~S}$ ribosomal RNA (rRNA), 5'-CGGGATCCATGAA GAAAAATTTAAG-3' for $s l p A$, 5'-AGGCCATACTGAAC TT-3' for $s l p B$, and 5'-ATCAAACTGCAACCATTC-3' for slpX. Reverse primers were as follows: 5'-GGCACTGAAG GGCGGAAACC-3' for $16 S$ rRNA, 5'-GTTGGTATTGA TTGCTGATG-3' for $s l p A$, 5'-AGTAGCTGAAACCTTG-3' for $\operatorname{slp} B$, and 5'-ACTTGGAATACTTGTCC-3' for $\operatorname{slp} X$. The concentration of the purified RNA was determined using a Nanodrop2000 spectrophotometer (Thermo Scientific, Waltham, MA, USA). The 16S rRNA gene was used as reference. Results were analyzed using the critical threshold $\left(\Delta \mathrm{C}_{\mathrm{T}}\right)$ and the comparative critical threshold $\left(\Delta \Delta \mathrm{C}_{\mathrm{T}}\right)$ method in the IQTM 5 Optical System Software (http://www.bio-rad. com/en-us/product/iq5-optical-system-software-version-2-1). Each sample was analyzed in triplicate, and samples from two independent experiments were analyzed for each condition. $\Delta \Delta \mathrm{C}_{\mathrm{T}}$ for $s l p$ genes related to $16 \mathrm{~S}$ ribosomal housekeeping gene was plotted as relative expression between control and high-salt conditions.

Cell wall purification fractions were prepared using the procedure described in Piuri et al. (2005) from cell cultures grown in MRS medium (low salt control conditions) or MRS medium containing $0.6 \mathrm{M} \mathrm{NaCl}$ (high-salt conditions). Briefly, cell walls obtained from bacterial cells were treated by heating at $100{ }^{\circ} \mathrm{C}$ in $4 \%(w / v)$ SDS for $60 \mathrm{~min}$, the nonlysed cells were removed by a short centrifugation step $(1500 \times \mathrm{g} 5 \mathrm{~min})$, and the cell walls were recovered by centrifugation at $20,000 \times \mathrm{g} 20 \mathrm{~min}$. Then, cell walls were washed five times in water and thereafter incubated with DNAse $(30 \mu \mathrm{g} / \mathrm{ml})$ and RNAse $(5 \mu \mathrm{g} / \mathrm{ml})$ for $2 \mathrm{~h}$ at $37^{\circ} \mathrm{C}$, followed by $0.5 \mathrm{mg}$ trypsin $\mathrm{ml}^{-1}$ at $37^{\circ} \mathrm{C}$ for $16 \mathrm{~h}$ in $0.1 \mathrm{M}$ Tris- $\mathrm{HCl}$ (pH 7.5). Peptidoglycan was obtained by treating cell walls overnight at $4{ }^{\circ} \mathrm{C}$ with $10 \%(w / v)$ trichloroacetic acid to eliminate wall teichoic acid polymers and then washing three times with water. LTA was purified using the 1-butanol extraction method (Palomino et al. 2013).

For the sequential degradation of amino acids from proteins and peptides, we used the Edman degradation method (1949). In this reaction, the $\mathrm{N}$-terminus reacts with phenylisothiocyanate in a basic medium. The derivatized amino acid is identified by reverse-phase liquid chromatography, with detection at $269 \mathrm{~nm}$. This identification is performed by comparison of the retention time with a standard containing all the 20 common derivatized amino acids in a Shimadzu sequencer PPSQ-31 (Kyoto, Japan) at the LANAIS-PROEM facility, CONICET, Buenos Aires, Argentina.

The electrophoretic bands obtained in SDS-PAGE corresponding to $\mathrm{S}$-layer protein were cut, destained in acetonitrile $(\mathrm{ACN}) / 20 \mathrm{mM} \mathrm{NH} \mathrm{HCO}_{3} \mathrm{pH} 8.5$ (1:1), dried at room temperature, rehydrated with $25 \mathrm{mM} \mathrm{NH}_{4} \mathrm{HCO}_{3}$, reduced with $10 \mathrm{mM}$ dithiothreitol, and alkylated with $55 \mathrm{mM}$ iodoacetamide in $25 \mathrm{mM} \mathrm{NH} \mathrm{HCO}_{3}$. Tryptic digestion was performed incubating each slice with $120 \mathrm{ng}$ of trypsin (Promega sequencing grade modified) in $20 \mathrm{mM} \mathrm{NH}_{4} \mathrm{HCO}_{3}$ pH 8.5 overnight at $37^{\circ} \mathrm{C}$. Peptides were extracted by incubating each slice with $50 \%$ acetonitrile (ACN) $0.5 \%$ trifluoroacetic acid (TFA). Aliquots of the extracted peptides were mixed $1: 1$ with the matrix ( $3 \mathrm{mg} / \mathrm{ml} 4$-hydroxy- $\alpha$-cyanocinnamic acid in $50 \%$ ACN $0.5 \%$ TFA), loaded onto MTP Anchor Chip Target (Bruker Daltonics, Billerica, MA, USA) for co-crystallization, and analyzed in an Ultraflex II MALDITOF/TOF mass spectrometer for mass spectrometry (MS) and MS/MS analysis in the MS facility of the Centro de Estudios Químicos y Biológicos por Espectrometría de Masa (CEQUIBIEM), Facultad de Ciencias Exactas y Naturales, Universidad de Buenos Aires, Argentina. The data were acquired in reflector mode from a mass range of 700 to $4000 \mathrm{Da}$, and 1250 laser shots were averaged for each mass spectrum. Each sample was internally calibrated with trypsin autolysis and keratin peaks. The peak list generated was based on signal-to-noise filtering and an exclusion list. The resulting file was then searched by Mascot (Matrix Science, Boston, MA, USA; http://www.matrixscience.com/search-formselect.html) with database search parameters, including a mass tolerance of 20-100 ppm, one missed cleavage, oxidation of methionines, and carbamidomethylation of cysteines. Only proteins matched with significant scores $(p<0.05)$ were considered. The hit obtained was validated by $\mathrm{MS} / \mathrm{MS}$ fragmentation of one or two high $\mathrm{S} / \mathrm{N}$ peaks per sample. 


\section{Results}

\section{S-layer content of $L$. acidophilus ATCC 4356 under high-salt conditions}

Since we have previously observed the importance of the envelope composition in the adaptation to salt stress of several gram-positive species and strains, here, we studied a Lactobacillus strain endowed of S-layers. Klaenhammer et al. (2005) reported that an slpA mutant of L. acidophilus NCFM is sensitive to $\mathrm{NaCl}$ and ethanol and resistant to bile. Here, we studied a different strain ( $L$. acidophilus ATCC 4356) and analyzed its response to salt stress during all the growth phases. The S-layer proteins from whole cells were analyzed by SDS-PAGE and western blot. In control conditions, we found only one predominant protein, whereas in high salt, we found two S-layer bands (Fig. 1a). We verified the immunological identity of both protein bands by detection with antibodies against SlpA in western blot (Fig. 1b) and zymogram analysis, which showed peptidoglycan hydrolase activity (Fig. 1c) (Prado-Acosta et al. 2008). As shown in Fig. 1a, for the control condition and the exponential phase, the predominant S-layer protein corresponded to a molecular weight (MW) of $45.9 \mathrm{kDa}$, representing more than $90 \%$ of the S-layers and a 49.4-kDa S-layer protein representing less than $10 \%$. In contrast, in high-salt and stationary phase, we observed an increase in the representation of the $49.4 \mathrm{kDa}$ protein. One possible explanation for the $3.5-\mathrm{kDa}$ difference between the two immunologically detected bands could be the processing of the N-terminal 31-amino-acid signal peptide of the 444-amino-acid SlpA protein (predicted ProtParamExPASy, http://web.expasy.org/protparam/, MW 46569.8 Da). The S-layer is translocated through the membrane to the extracellular medium by a 31-amino-acid signal peptide, which is cleaved to give a mature S-layer protein, resulting in about 3-kDa difference (Sára and Sleytr 2000). We next sequenced the $\mathrm{N}$-terminus of the $45.9 \mathrm{kDa}$ protein extracted with $5 \mathrm{M} \mathrm{LiCl}$ through the Edman degradation method (1949) and found that the processed protein is actually 413 amino acids long, beginning with the sequence ATTINA, having positive
Fig. 1 A $12.5 \%$ SDS-PAGE profile of whole-cell proteins $(10 \mu \mathrm{lOD} 600=1)(\mathbf{a})$, western blot $(20 \mu \mathrm{l}$ OD600 = 5) (b), and zymogram analysis of whole-cell proteins (c) from Lactobacillus acidophilus ATCC 4356 grown under different conditions: control condition in MRS $(C)$ or with $\mathrm{NaCl}(N$, numbers express molarities) from the exponential and stationary phases. Double and single asterisks show the 49.4 and $45.9 \mathrm{kDa}$ protein, respectively
A Exponential Stationary
MK S-lay
N
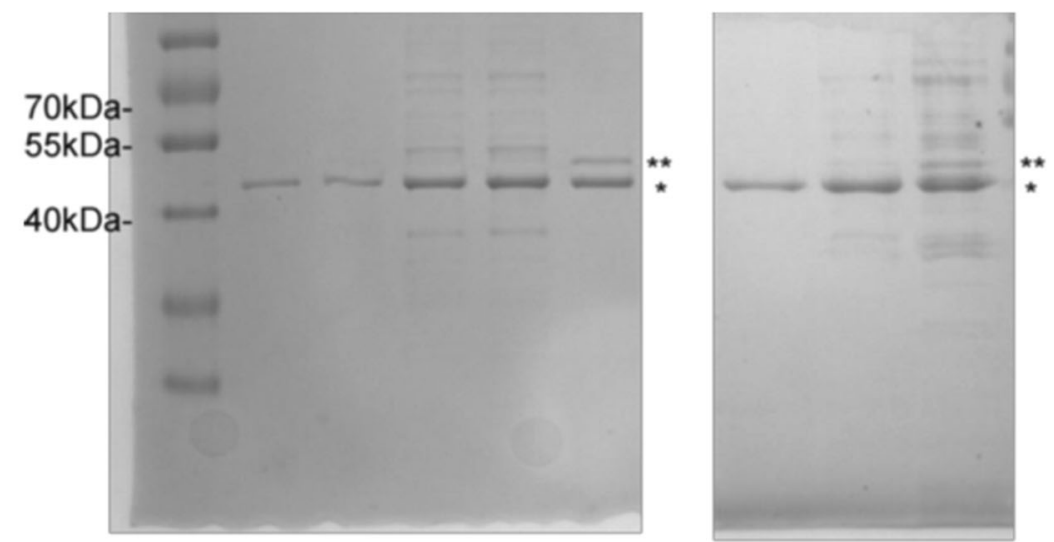

B

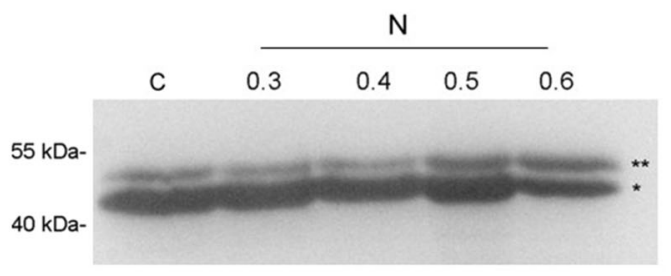

C

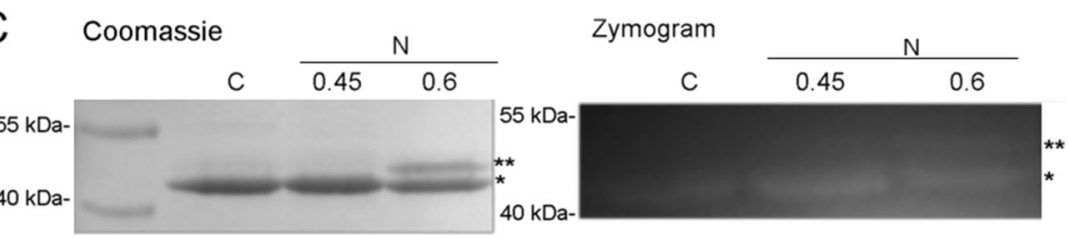


charge (pI 9.49) and being still insoluble in aqueous solution by interaction between monomers as described for other Slayers (Avall-Jääskeläinen et al. 2008) with a predicted ProtParam MW (ExPASy) of 43,635.3 Da. Therefore, a reduction of the processing of the signal peptide in the high-salt growth condition might explain the two bands observed. However, no intracellular increase in the precursor accumulated was verified from sonicated whole cells analyzed by western blot (data not shown). When both proteins were analyzed by MS (Supplemental Fig. S2 and Table S2), the predominant SlpA and the auxiliary SlpX were identified. Increasing $\mathrm{NaCl}$ in the growth medium changed the S-layer pattern: at $0.6-\mathrm{M} \mathrm{NaCl}$ concentration, the proportion of SlpA was up to $60 \%$, whereas that of SlpX increased to $40 \%$ (Fig. 1b). The $49.4 \mathrm{kDa}$ protein might result from the processing of the signal peptide of SlpX 499-amino-acid protein (ProtParam predicted 54,194 Da), giving a 467-amino-acid protein with a predicted ProtParam MW of 50,946.2 Da, although the discrepancy between the estimated and predicted MW observed would probably be due to an amino acid modification or to its cationic nature. In fact, sequencing of the $\mathrm{N}$ terminus of SlpX was not possible due to a probable modification.

\section{High salt increases $\operatorname{sip} A$ and $\operatorname{slp} X$ gene expression}

Three $\operatorname{slp}$ genes, $\operatorname{slp} A, \operatorname{slp} B$, and $\operatorname{slp} X$, are annotated in the genome of $L$. acidophilus. Since the three proteins have high amino acid sequence similarity (Supplemental Fig. S1), immunological cross-reactivity is expected and observed. The discrepancy between the estimated and predicted MW is probably due to an amino acid modification and to the cationic nature of these proteins. Therefore, we focused on analyzing the gene expression of $\operatorname{slp} A, \operatorname{slp} B$, and $\operatorname{slp} X$ to confirm the switch in high salt. The expression of $\operatorname{slp} A$ and $\operatorname{slp} X$ increased as the salt concentration of the culture medium increased, whereas that of $\operatorname{slp} B$ remained silent (Fig. 2), in concordance with previous reports where attempts to demonstrate expression of the $\operatorname{slp} B$ gene were unsuccessful (Boot et al. 1996; Pouwels et al. 1997).

To verify whether the transcription and translation of the Slayer genes and proteins in the high-salt condition are directly correlated (Fig. 1a), we analyzed the S-layer titer by immunological detection, in each growth condition obtained from the dot blot analysis. The high-salt conditions $(0.45$ and $0.6 \mathrm{M}$ $\mathrm{NaCl}$ ) in stationary phase gave the highest titers between 128 and 256, compared to 64 for all the other conditions (Supplemental Fig. S3). However, the transcription level was higher than the protein content. Thus, the correlation seems not to be completely strict in the case of the S-layer protein content, suggesting that the cell wall composition, structure, or additional factors may be involved.

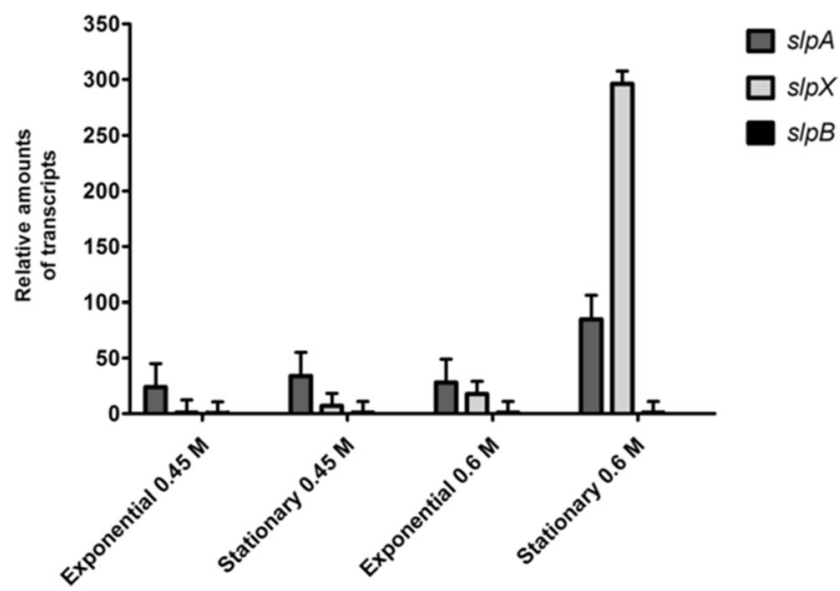

Fig. 2 Expression of $s l p$ genes by qPCR. Relative transcription between high-salt and control conditions is plotted. Bars express the level of expression for each gene normalized to that of rRNA 16S for each condition. Bars show standard errors from three independent experiments with duplicate samples

\section{Modification of the cell wall by high salt}

We have previously reported modifications of the cell wall structure of $L$. casei in high-salt conditions (Piuri et al. 2005; Palomino et al. 2013). The increase in the S-layer proteins in high-salt medium, involving active transcription of S-layer genes, could be due to a direct stress or to the response of the genes, to the modification of the cell wall (needing more S-layer to counteract its fragility), or to both. Therefore, here, we analyzed the cell wall and peptidoglycan in control and high-salt growth conditions. SDS extraction of total cell wall was significantly lower for $L$. acidophilus than for the non-Slayer-forming $L$. casei species. Cell wall yield obtained from L. acidophilus was almost one third and one fifth of that obtained from $L$. casei in control and high-salt growth conditions, respectively (Table 1 ). In fact, $L$. acidophilus cells grown in high salt showed peptidoglycan to be highly fragile, as verified by rapid autolysis upon successive water washes, with an almost 2-fold decrease in the peptidoglycan layer

Table 1 Cell envelope structure of Lactobacillus acidophilus ATCC 4356 in the presence or absence of $0.6 \mathrm{M} \mathrm{NaCl}$ and L. casei BL23

\begin{tabular}{llll}
\hline Sample $^{\mathrm{d}}$ & $\mathrm{CW}^{\mathrm{a}}$ & $\mathrm{PG}^{\mathrm{b}}$ & $\mathrm{LTA}^{\mathrm{c}}$ \\
\hline L. acidophilus & $15.0 \pm 1.0 \mathrm{mg}$ & $7.5 \pm 0.8 \mathrm{mg}$ & $0.23 \pm 0.02 \mathrm{mg}$ \\
L. acidophilus & $10.5 \pm 1.0 \mathrm{mg}$ & $4.5 \pm 0.5 \mathrm{mg}$ & $0.08 \pm 0.01 \mathrm{mg}$ \\
$\quad$ NaCl 0.6 M & $50.0 \pm 3.0 \mathrm{mg}$ & $35.0 \pm 2.0 \mathrm{mg}$ & $0.56 \pm 0.03 \mathrm{mg}$ \\
\begin{tabular}{l} 
L. casei \\
\hline
\end{tabular}
\end{tabular}

$C W$ cell wall, $P G$ peptidoglycan, $L T A$ lipoteichoic acid

${ }^{\text {a }}$ Insoluble material from cells extracted with $4 \%$ SDS at $100{ }^{\circ} \mathrm{C}$

${ }^{\mathrm{b}}$ Insoluble material from cell walls extracted with $10 \%$ trichloroacetic acid

${ }^{\mathrm{c}}$ Measured as phosphorus from butanol-extracted cells

${ }^{\mathrm{d}}$ Results are expressed per gram of dry weight 
when compared to the control condition. LTA mass recovery from strains grown in high-salt conditions was 3-fold lower than that in the control condition (Table 1), showing the same adaptation as that described in L. casei (Palomino et al. 2013).

A decrease in peptidoglycan might favor the detachment of the S-layer to the growth medium. To verify whether this was true, we determined the amount of S-layers in the supernatant. Western blot analysis of concentrated supernatants showed increased release of S-layer protein to the supernatant in high-salt stationary phase compared to the exponential phase (Fig. 3). This release to the supernatant might partly explain the fate of the protein synthesis by the increased transcription.

\section{Growth and S-layer formation}

To verify the influence of the S-layer proteins in the growth capacity in high-salt condition, we compared the growth of the wild-type strain in control medium to that of a strain subjected to the removal of the S-layer with $5 \mathrm{M} \mathrm{LiCl}$. Optimum removal with $5 \mathrm{M} \mathrm{LiCl}$ rather than with $1 \mathrm{M} \mathrm{LiCl}$ was verified (Fig. 4a). This strategy had been previously used to verify the influence of surface properties in the adhesion capacity and survival to gastric juice conditions for other L. acidophilus strains (Kos et al. 2003; Frece et al. 2005). This strategy did not reduce their viability or viable counts correlated with the growth rates (data not shown). However, severe growth defects were observed as salt concentration increased (Fig. 4b). Removal of the S-layer by $\mathrm{LiCl}$ treatment caused a delayed growth, even in the absence of $\mathrm{NaCl}$ stress, since the treatment may remove, denature, or affect other cell envelope components. Thus, although a differential behavior between control growth conditions and extremely high salt $(0.8 \mathrm{M} \mathrm{NaCl})$ is clearly observed, suggesting the influence of the S-layer, the growth defects observed at high $\mathrm{NaCl}$ in S-layer-depleted cells cannot be attributed only to the role of the S-layer in the osmoadaptive stress response. As shown in Fig. 4c, delayed recovery of S-layer synthesis at high salinity was correlated with the delayed growth observed under osmotic stress.

\section{Discussion}

It has been proposed that the S-layer plays a role as a protective sheath and that it may protect the bacterial cell from various environmental factors such as mechanical and osmotic stresses in Lactobacillus (Hynönen and Palva 2013; Gerbino et al. 2015). The need for the cell to increase S-layer gene expression is related to the integrity of the cell envelope structure. Although a correlation between transcription and translation is expected, this was not completely observed in the case of the S-layer proteins. What we found was that a great proportion of the S-layer protein is released to the supernatant. Nevertheless, we cannot discard an increased proteolytic activity in high-salt conditions as that described for $L$. casei (Piuri et al. 2003), which might influence the final concentration of protein located on the surface. This probable event, together with the shedding release to the supernatant, explains that transcription-translation results did not correlate strictly.

The requirement of the S-layer for growth even in normal conditions in the strains carrying S-layer like L. acidophilus could be explained by the 3-fold lower amount of peptidoglycan found when compared to a non-S-layer producer as L. casei (Table 1). Under high-salt conditions, a 2-fold decrease in peptidoglycan and increased fragility determined the need of the external highly compact S-layer component. The fragility of the cell walls of Lactobacillus strains carrying S-layers may be due to the presence of the S-layer or, otherwise, seems to force these strains to be dependent on the presence of the S-layer for growth. In fact, analysis of exoproteome profiles comparing Lactobacillus S-layercontaining species with non-forming species showed very few proteins isolated from the non-S-layer-forming species and increased extracellular proteins obtained by $\mathrm{LiCl}$ extraction from S-layer-containing species (Johnson et al.

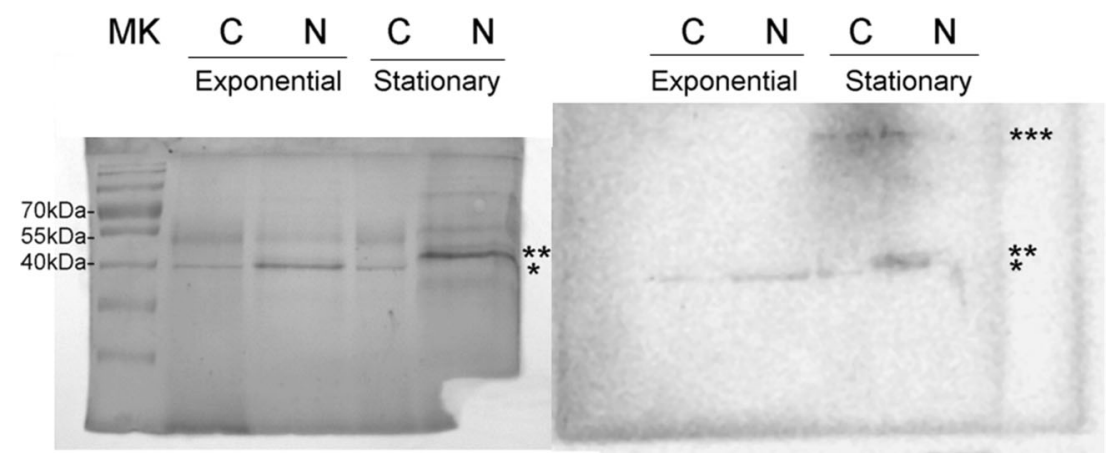

Fig. 3 A $12.5 \%$ SDS-PAGE profile (a) and western blot (b) of 20-fold concentrated supernatants recovered from Lactobacillus acidophilus ATCC 4356 grown under different conditions: control condition $(C)$ or with $\mathrm{NaCl}(N, 0.6 \mathrm{M} \mathrm{NaCl})$ from exponential and stationary phases. Double and single asterisks show the 49.4 and $45.9 \mathrm{kDa}$ protein, respectively. The triple asterisks show the position of S-layer multimers 

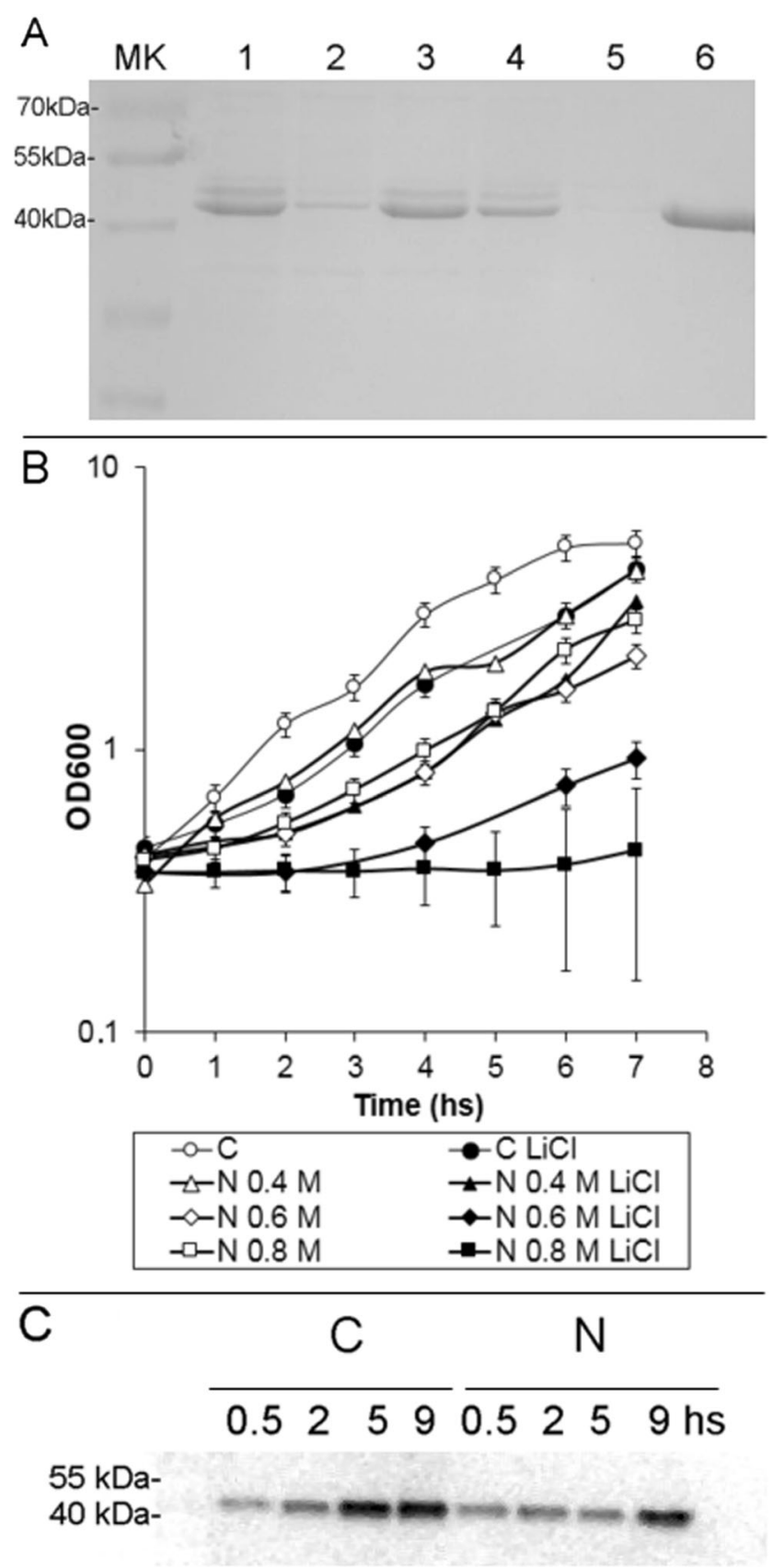

Fig. 4 A a $12.5 \%$ SDS-PAGE profile of whole cells extracted with different $\mathrm{LiCl}$ concentrations: MW markers $(M K)$, whole cells grown in $\mathrm{NaCl} 0.6 \mathrm{M}$ (lane 1), $1 \mathrm{M} \mathrm{LiCl-extracted} \mathrm{proteins} \mathrm{in} \mathrm{NaCl} 0.6 \mathrm{M}$ condition (lane 2), $5 \mathrm{M} \mathrm{LiCl}$-extracted proteins in $\mathrm{NaCl} 0.6 \mathrm{M}$ condition (lane 3), control cells (lane 4), $1 \mathrm{M} \mathrm{LiCl-extracted} \mathrm{control} \mathrm{cells} \mathrm{(lane} \mathrm{5),}$ $5 \mathrm{M} \mathrm{LiCl-extracted} \mathrm{control} \mathrm{cells} \mathrm{(lane} \mathrm{6).} \mathrm{b} \mathrm{Growth} \mathrm{curves} \mathrm{of}$ Lactobacillus acidophilus ATCC 4356 with (empty symbols) and without (filled symbols) S-layer. Cells were grown in control medium $(C)$ and high-salt medium $(N=0.4,0.6$, or $0.8 \mathrm{M} \mathrm{NaCl})$. Error bars represent standard errors from three replicate experiments. c Effect of $\mathrm{NaCl}$ in $\mathrm{S}-$ layer synthesis. Cells of L. acidophilus ATCC 4356 were treated with $\mathrm{LiCl} 5 \mathrm{M}$ to remove the S-layer and then recovered in control medium $(C)$ or salt medium $(0.6 \mathrm{M} \mathrm{NaCl})$. Aliquots $(15 \mu \mathrm{l})$ were taken at different times and loaded to $12.5 \%$ SDS-PAGE and western blot detection
2015). This observation suggests that an increased association of proteins to the surface layer might participate in maintaining cell wall stability, probably due to the fragility associated with fewer peptidoglycan layers in other S-layer-containing species as that observed for L. acidophilus. This hypothesis is the aim of our future work.

As we have described earlier, an slpA mutant of $L$. acidophilus NCFM has been reported to be osmosensitive (Klaenhammer et al. 2005). In addition, it has been suggested that the auxiliary S-layer component SlpX of L. acidophilus NCFM affects the permeability of the S-layer as the $\operatorname{sl} \mathrm{X}$-negative mutant is more susceptible to SDS and more resistant to bile than the wild type (Goh et al. 2009). Challenging of the slp $X$-negative mutant with $10 \% \mathrm{NaCl}$ gave no significant difference in the survival rate, probably because the absence of one $s l p$ gene was compensated by the overexpression of another (Goh et al. 2009). The presence of multiple S-layer protein genes in the same strain is a common feature in lactobacilli. The strict requirement of the S-layer for growth in normal conditions has been stated by Goh et al. (2009); even if an slp mutant was obtained in the L. acidophilus NCFM background, the absence of one slp gene was compensated by the overexpression of another $s l p$ not usually expressed. A knockout mutant of $s l p$ genes of L. acidophilus NCFM expressed $\operatorname{slpA}$ and $\operatorname{slpX}$ or $\operatorname{slp} B$ and $\operatorname{slp} X$ simultaneously (Goh et al. 2009). This argues in favor of the statement by Hynönen and Palva (2013) based on their unpublished results about the difficulty or impossibility to create completely S-layer-negative Lactobacillus mutants, indicating that at least one functional S-layer protein gene is essential for the growth of S-layer-carrying lactobacilli. Therefore, since double mutants are probably non-viable (Hynönen and Palva 2013), it is difficult to firmly conclude that S-layers are essential for the osmoadaptation of L. acidophilus ATCC 4356.

As shown in the present study, S-layer proteins are present during all growth phases and the genes are preferentially expressed in the stationary phase and in the presence of $0.6 \mathrm{M} \mathrm{NaCl}$ (Figs. 1 and 2). Schär-Zammaretti et al. (2005) showed that the expression of the S-layer protein gene of L. acidophilus NCC 2628 is induced when the strain is grown under conditions of limited protein supply. Other authors have shown that S-layer production in L. acidophilus is increased under other stress conditions (Khaleghi et al. 2010; 2011). However, these authors used mild stress conditions ( 1 to $3 \% \mathrm{NaCl}$ ) and focused only on $\operatorname{slp} A$ gene expression, without analyzing $\operatorname{slp} X$. In the present study, we found that increasing $\mathrm{NaCl}$ concentration over $0.6 \mathrm{M}(3.5 \% w / v)$ is required to verify the role of the auxiliary S-layer component SlpX. Similarly, in Lactobacillus brevis ATCC 14869, JakavaViljanen et al. (2002) found that the differential expression of the $\operatorname{slp} B$ and $\operatorname{slp} D$ genes is related to the oxygen content of the growth medium and the growth stage. 
This upregulated expression of $\operatorname{slp} A$ and $\operatorname{slp} X$ in high-salt conditions agrees with an increase in S-layer protein synthesis, modifying the proportion between SlpX and SlpA in the Slayer profile in high-salt growth conditions. In fact, our results show a switch to increase the quantity of S-layer proteins due to the high-salt conditions, rendering a modified S-layer profile between SlpX and SlpA when both conditions are compared. This modified S-layer profile resembles the developmental switch or antigenic variation of S-layer protein synthesis in Bacillus anthracis (Fouet 2009; Mignot et al. 2002). Since it has been verified that the inversion of the $s l p$ segment between $\operatorname{slp} A$ and $\operatorname{slp} B$ takes place only in very few cells (Boot et al. 1996), it is not surprising that $\operatorname{sip} B$ was not detected in the present study.

We also found that the processing of the signal peptide of the SlpA protein renders a 413-amino-acid mature protein beginning with the sequence ATTINA, as described for other Lactobacillus species (Lortal et al. 1992; Vidgrén et al. 1992; Sillanpää et al. 2000; Ventura et al. 2000; Sára and Sleytr 2000; Hynönen et al. 2014).

Recently, the adaptation of probiotics to stress conditions has been analyzed (Khaleghi 2010; 2011) and reviewed (Mills et al. 2011), and results have shown that general stress response, DNA repair, and energy metabolism favor increased survival during exposure to stressful conditions. We propose, for biotechnological applications, that pre-growth of lactobacilli in high-salt conditions would result in an advantage for the probiotic nature of cells: the increased production and release of the S-layer might be appropriate for their antimicrobial capacity (Prado-Acosta et al. 2008, 2010; Martínez et al. 2012; Meng et al. 2015). Also, the reduction of the LTA content needs to be evaluated for possible anti-inflammatory (Kim et al. 2014; Kaji et al. 2010) or inflammatory effects (Lebeer et al. 2012; Mohamadzadeh et al. 2011; Zadeh et al. 2012). This is necessary to determine the benefit of pregrowth in high-salt conditions for the design of a probiotic formulation. We are currently evaluating the influence of high-salt stress on the expression of LTA genes in L. acidophilus and the survival to gut-simulated conditions of cells pre-grown in high-salt conditions.

In summary, in this work, we found that S-layer proteins are involved in the adaptation of $L$. acidophilus to osmotic stress. We showed, for the first time, an increased expression of the SlpX protein due to high-salt conditions, accompanying the predominant S-layer protein SlpA. Our results suggest that a variation in the pattern of S-layer expression in stress conditions (salt growth phase) would be linked to the overall stress responses of this species. Moreover, the importance of the fragility of the cell wall observed for L. acidophilus, when compared to other non-S-layer-forming $L$. casei, would strongly support the need of this additional envelope.

The transcriptional and translational regulation mechanisms of Lactobacillus S-layer protein genes on a molecular level are unexplored. Overexpression of $s l p$ genes might be attributed to the release of a genetic regulation, and this will be the aim of our future investigations.

\section{Compliance with ethical standards}

Ethical approval This article does not contain any studies with human participants or animals performed by any of the authors.

Funding This work was supported by grants from the Universidad de Buenos Aires 20020130100444BA and the Agencia de Promocion Científica y Tecnológica PICT2012-0789 Argentina to SMR. PMW and JFM are graduate fellows of ANPCyT and CONICET, respectively.

Conflict of interest The authors declare that they have no competing interests.

\section{References}

Ashida N, Yanagihara S, Shinoda T, Yamamoto N (2011) Characterization of adhesive molecule with affinity to Caco-2 cells in Lactobacillus acidophilus by proteome analysis. J Biosci Bioeng 112:333-337. doi:10.1016/j.jbiosc.2011.06.001

Avall-Jääskeläinen S, Palva A (2005) Lactobacillus surface layers and their applications. FEMS Microbiol Rev 29:511-529

Avall-Jääskeläinen S, Hynönen U, Ilk N, Pum D, Sleytr UB, Palva A (2008) Identification and characterization of domains responsible for self-assembly and cell wall binding of the surface layer protein of Lactobacillus brevis ATCC 8287. BMC Microbiol 8:165. doi:10.1186/1471-2180-8-165

Boot HJ, Kolen CP, Pouwels PH (1996) Interchange of the active and silent S-layer protein genes of Lactobacillus acidophilus by inversion of the chromosomal slp segment. Mol Microbiol 21:799-809

Buck BL, Altermann E, Svingerund T, Klaenhammer TR (2005) Functional analysis of putative adhesion factors in Lactobacillus acidophilus NCFM. Appl Environ Microbiol 71:8344-8351

Capozzi V, Arena MP, Crisetti E, Spano G, Fiocco D (2011) The hsp 16 gene of the probiotic Lactobacillus acidophilus is differently regulated by salt, high temperature and acidic stresses, as revealed by reverse transcription quantitative PCR (qRT-PCR) analysis. Int J Mol Sci 12:5390-5405. doi:10.3390/ijms12085390

Crow VL, Coolbear T, Gopal PK, Martley FG, McKay LL, Riepe H (1995) The role of autolysis of lactic acid bacteria in the ripening of cheese. Int Dairy J 5:855-875

Edman P (1949) A method for the determination of amino acid sequence in peptides. Arch Biochem Biophys 22:475-480

Fouet A (2009) The surface of Bacillus anthracis. Mol Asp Med 30: 374-385. doi:10.1016/j.mam.2009.07.001

Fox PF, Wallace JM, Morgan S, Lynch CM, Niland EJ, Tobin J (1996) Acceleration of cheese ripening. Antonie Van Leeuwenhoek 70: 271-297

Frece J, Kos B, Svetec IK, Zgaga Z, Mrsa V, Suskovic J (2005) Importance of S-layer proteins in probiotic activity of Lactobacillus acidophilus M92. J Microbiol Res 1:65-78

Gerbino E, Carasi P, Mobili P, Serradell MA, Gómez-Zavaglia A (2015) Role of S-layer proteins in bacteria. World J Microbiol Biotechnol 31:1877-1887. doi:10.1007/s11274-015-1952-9

Goh YJ, Azcárate-Peril MA, O’Flaherty S, Durmaz E, Valence F, Jardin J, Lortal S, Klaenhammer TR (2009) Development and application of a upp-based counterselective gene replacement system for the study of the S-layer protein SlpX of 
Lactobacillus acidophilus NCFM. Appl Environ Microbiol 75: 3093-3105. doi:10.1128/AEM.02502-08

Hynönen U, Palva A (2013) Lactobacillus surface layer proteins: structure, function and applications. Appl Microbiol Biotechnol 97: 5225-5243. doi:10.1007/s00253-013-4962-2

Hynönen U, Kant R, Lähteinen T, Pietilä TE, Beganović J, Smidt H, Uroić K, Avall-Jääskeläinen S, Palva A (2014) Functional characterization of probiotic surface layer protein-carrying Lactobacillus amylovorus strains. BMC Microbiol 14:199. doi:10.1186/14712180-14-199

Jakava-Viljanen M, Avall-Jääskeläinen S, Messner P, Sleytr UB, Palva A (2002) Isolation of three new surface layer protein genes $(s l p)$ from Lactobacillus brevis ATCC 14869 and characterization of the change in their expression under aerated and anaerobic conditions. $\mathrm{J}$ Bacteriol 184:6786-6795

Johnson BR, Hymes J, Sanozky-Dawes R, Henriksen ED, Barrangou R, Klaenhammer TR (2015) Conserved S-layer-associated proteins revealed by exoproteomic survey of S-layer-forming lactobacilli. Appl Environ Microbiol 82:134-145. doi:10.1128 /AEM.01968-15

Kaji R, Kiyoshima-Shibata J, Nagaoka M, Nanno M, Shida K (2010) Bacterial teichoic acids reverse predominant IL-12 production induced by certain Lactobacillus strains into predominant IL-10 production via TLR2-dependent ERK activation in macrophages. J Immunol 184:3505-3513. doi:10.4049/jimmunol.0901569

Kets E, Teunissen P, de Bont J (1996) Effect of compatible solutes on survival of lactic acid bacteria subjected to drying. Appl Environ Microbiol 62:259-261

Khaleghi M, Kermanshahi RK (2012) Effect of environmental stresses on S-layer production in Lactobacillus acidophilus ATCC 4356. In: Petre M (ed) Advances in applied biotechnology, chapter 11. InTech, Rijeka. doi:10.5772/28334

Khaleghi M, Kasra Kermanshahi R, Yaghoobi MM, Zarkesh-Esfahani SH, Baghizadeh A (2010) Assessment of bile salt effects on Slayer production, slp gene expression and, some physicochemical properties of Lactobacillus acidophilus ATCC 4356. J Microbiol Biotechnol 20:749-756

Kim H, Jung BJ, Jeong J, Chun H, Chung DK (2014) Lipoteichoic acid from Lactobacillus plantarum inhibits the expression of plateletactivating factor receptor induced by Staphylococcus aureus lipoteichoic acid or Escherichia coli lipopolysaccharide in human monocyte-like cells. J Microbiol Biotechnol 24:1051-1058

Klaenhammer TR, Barrangou R, Buck BL, Azcarate-Peril MA, Altermann E (2005) Genomic features of lactic acid bacteria effecting bioprocessing and health. FEMS Microbiol Rev 29: 393-409

Koch S, Oberson G, Eugster-Meier E, Meile L, Lacroix C (2007) Osmotic stress induced by salt increases cell yield, autolytic activity, and survival of lyophilization of Lactobacillus delbrueckii subsp. lactis. Int J Food Microbiol 117:36-42

Kos B, Suskovic J, Vukovic S, Simpraga M, Frece J, Matosic S (2003) Adhesion and aggregation ability of probiotic strain Lactobacillus acidophilus M92. J Appl Microbiol 94:981-987

Lebeer S, Claes IJ, Vanderleyden J (2012) Anti-inflammatory potential of probiotics: lipoteichoic acid makes a difference. Trends Microbiol 840:1-6. doi:10.1016/j.tim.2011.09.004

Lopez CS, Heras H, Garda H, Ruzal S, Sanchez-Rivas C, Rivas E (2000) Biochemichal and biophysical studies of Bacillus subtilis envelopes under hyperosmotic stress. Int J Food Microbiol 55:137-142

Lortal S, van Heijenoort J, Gruber K, Sleytr UB (1992) S-layer of Lactobacillus helveticus ATCC 12046: isolation, chemical characterization and reformation after extraction with lithium chloride. $\mathrm{J}$ Gen Microbiol 138:611-618

Martínez MG, Prado Acosta M, Candurra N, Ruzal SM (2012) S-layer proteins of Lactobacillus acidophilus inhibits JUNV infection. BBRC 422:590-595. doi:10.1016/j.bbrc.2012.05.031
Meng J, Gao SM, Zhang QX, Lu RR (2015) Murein hydrolase activity of surface layer proteins from Lactobacillus acidophilus against Escherichia coli. Int J Biol Macromol 79:527-532. doi:10.1016/j. ijbiomac.2015.03.057

Mignot T, Mesnage S, Couture-Tosi E, Mock M, Fouet A (2002) Developmental switch of S-layer protein synthesis in Bacillus anthracis. Mol Microbiol 43:1615-1627

Mills S, Stanton C, Fitzgerald GF, Ross RP (2011) Enhancing the stress responses of probiotics for a lifestyle from gut to product and back again. Microb Cell Factories 10(Suppl 1):S19. doi:10.1186/14752859-10-S1-S19

Mohamadzadeh M, Pfeiler EA, Brown JB, Zadeh M, Gramarossa M, Managlia E, Bere P, Sarraj B, Khan MW, Pakanati KC, Ansari MJ, O'Flaherty S, Barrett T, Klaenhammer TR (2011) Regulation of induced colonic inflammation by Lactobacillus acidophilus deficient in lipoteichoic acid. Proc Natl Acad Sci U S A 108:4623-4630. doi:10.1073/pnas.1005066107

O'Flaherty SJ, Klaenhammer TR (2010) Functional and phenotypic characterization of a protein from Lactobacillus acidophilus involved in cell morphology, stress tolerance and adherence to intestinal cells. Microbiology 156:3360-3367. doi:10.1099/mic.0.043158-0

Palomino MM, Allievi MC, Fina Martin J, Waehner PM, Prado Acosta M, Sanchez Rivas C, Ruzal SM (2015) Draft genome sequence of the probiotic strain Lactobacillus acidophilus ATCC 4356. Genome Announc. doi:10.1128/genomeA.01421-14

Palomino MM, Allievi MC, Gründling A, Sanchez-Rivas C, Ruzal SM (2013) Osmotic stress adaptation in Lactobacillus casei BL23 leads to structural changes in the cell wall polymer lipoteichoic acid. Microbiology 159:2416-2426. doi:10.1099/mic.0.070607-0

Palomino MM, Prado Acosta M, Allievi MC, Sabbione F, Sanchez Rivas C, Ruzal SM (2010) New method for electroporation of Lactobacillus species grown in high salt. J Microbiol Methods 83: 164-167. doi:10.1016/j.mimet.2010.08.017

Palomino MM, Sanchez Rivas C, Ruzal SM (2009) High salt stress in Bacillus subtilis: involvement of PBP4* as a peptidoglycan hydrolase. Res Microbiol 160:117-124. doi:10.1016/j. resmic.2008.10.011

Piuri M, Sanchez-Rivas C, Ruzal SM (2003) Adaptation to high salt in Lactobacillus: role of peptides and proteolytic enzymes. J Appl Microbiol 95:372-379

Piuri M, Sanchez-Rivas C, Ruzal SM (2005) Cell wall modifications during osmotic stress in Lactobacillus casei. J Appl Microbiol 98: 84-95

Pouwels P, Kolen CPAM, Boot HJ (1997) S-layer protein genes in Lactobacillus. FEMS Microbiol Rev 20:78-82

Prado-Acosta M, Palomino MM, Allievi MC, Sanchez Rivas C, Ruzal SM (2008) The S-layer of Lactobacillus acidophilus ATCC 4356 shows murein hydrolase activity. Appl Environ Microbiol 74:78247827. doi:10.1128/AEM.01712-08

Prado-Acosta M, Ruzal SM, Palomino MM, Allievi MC, Sanchez Rivas C (2010) Synergistic effects of the Lactobacillus acidophilus S-layer and nisin on bacterial growth. Appl Environ Microbiol 6:974-977. doi:10.1128/AEM.01427-09

Ramiah K, van Reenen CA, Dicks LMT (2009) Expression of the mucus adhesion gene $m u b$, surface layer protein slp and adhesion-like factor EF-TU of Lactobacillus acidophilus ATCC 4356 under digestive stress conditions, as monitored with real-time PCR. Probiotics \& Antimicrobial Proteins 1:91-95. doi:10.1007/s12602-009-9009-8

Resta-Lenert S, Barrett KE (2003) Live probiotics protect intestinal epithelial cells from the effects of infection whit enteroinvasive Escherichia coli (EIEC). Gut 52:988-997

Sára M, Sleytr UB (2000) S-layer proteins. J Bacteriol 182:859-868

Schär-Zammaretti P, Dillmann M-L, D’Amico N, Affolter M, Ubbink J (2005) Influence of fermentation medium composition on physicochemical surface properties of Lactobacillus acidophilus. Appl Environ Microbiol 71:8165-8173 
Sillanpää J, Martínez B, Antikainen J, Toba T, Kalkkinen N, Tankka S, Lounatmaa K, Keränen J, Höök M, Westerlund-Wikström B, Pouwels PH, Korhonen TK (2000) Characterization of the collagen-binding S-layer protein CbsA of Lactobacillus crispatus. J Bacteriol 182:6440-6450

Smit E, Jager D, Martinez B, Tielen FJ, Pouwels PH (2002) Structural and functional analysis of the S-layer protein crystallisation domain of Lactobacillus acidophilus ATCC 4356: evidence for proteinprotein interaction of two subdomains. J Mol Biol 324:953-964

Smit E, Oling F, Demel R, Martinez B, Pouwels PH (2001) The S-layer protein of Lactobacillus acidophilus ATCC 4356: identification and characterisation of domains responsible for S-protein assembly and cell wall binding. J Mol Biol 305:245-257

Ventura M, Callegari ML, Morelli L (2000) S-layer gene as a molecular marker for identification of Lactobacillus helveticus. FEMS Microbiol Lett 189:275-279
Vidgrén G, Palva I, Pakkanen R, Lounatmaa K, Palva A (1992) S-layer protein gene of Lactobacillus brevis: cloning by polymerase chain reaction and determination of the nucleotide sequence. J Bacteriol 174:7419-7427

Weiss G, Jespersen L (2010) Transcriptional analysis of genes associated with stress and adhesion in Lactobacillus acidophilus NCFM during the passage through an in vitro gastrointestinal tract model. J Mol Microbiol Biotechnol 18:206-214. doi:10.1159/000316421

Zadeh M, Khan MW, Goh YJ, Selle K, Owen JL, Klaenhammer T, Mohamadzadeh M (2012) Induction of intestinal pro-inflammatory immune responses by lipoteichoic acid. J Inflamm (Lond) 9:7. doi:10.1186/1476-9255-9-7 